\title{
Investigating the Relationship Between Second Language Writing Proficiency and Noun Modifications
}

\author{
Ge Lan \\ Northern Arizona University, Flagstaff, Arizona, USA
}

\begin{abstract}
This research investigated the relationship between second language (L2) writing proficiency and noun modifications in the context of the Program of Intensive English (PIE) at Northern Arizona University (NAU). In the research, a computer-counting program was used to check 12 noun modifiers in an index of L2 writing development in two tagged corpora that were built based on 84 PIE test essays. The two tagged corpora consist of a corpus of lower L2 writing proficiency and a corpus of higher L2 writing proficiency respectively. The results show that there are significant differences in the frequencies of some noun modifiers, especially post-noun modifiers, between the two corpora. To be more specific, students with higher L2 writing proficiency used relative clauses and prepositional phrases statistically more than students with lower L2 writing proficiency did. However, some noun modifiers were rarely used by all students, such as nonfinite clauses, infinitive clauses, and appositive noun phrases, to name a few. Consequently, English as a second language (ESL) instructors may organize writing workshops to teach different noun modifiers to students with different writing proficiencies. By doing this, it could help students effectively develop their L2 writing proficiency.
\end{abstract}

Keywords: corpus-based, second language (L2) writing proficiency, noun modifiers

\section{Introduction}

Second language (L2) writing has received intensive attention in the field of applied linguistics in the past several decades. Numerous studies have been carried out to discover some primary aspects of L2 writing (i.e., accuracy, fluency, and complexity). Currently, corpus-based studies reveal an important role that noun phrase complexity plays in academic writings: Phrasal modifications in noun phrases have been proved to be one of the most frequent linguistic features in academic writing (Biber, Gray, \& Poonpon, 2013). Meanwhile, a hypothesized developmental index of L2 writing complexity was proposed, associating 5 sequential developmental stages of L2 writing with a bunch of linguistic features (Biber, Gray, \& Poonpon, 2011). In this study, the author planned to explore whether noun modifiers are able to mirror L2 writing proficiency in academic writings through analyzing the relationship between them in essays of a language proficiency test.

\section{Literature Review}

In the field of academic writing, researchers have believed for a long time there is a strong relationship between grammatical complexity and clausal subordination (Biber et al., 2013). Back in the 1980s,

Ge Lan, M.A. TESL candidate, Master of Arts (in progress), English Department, Northern Arizona University. 
Huddleston (1984) argued that dependent clauses are the most important linguistic features for academic writing. From then on, T-units became a professional way to evaluate the grammatical complexity in academic writing. According to Hunt (1965), T-units refer to a main clause and all the subordinate clauses attached to it. However, recent research studies subsume some critical reviews on the T-unit-based measure, which could be categorized into two general domains: (1) its lack of utility in testing application and (2) its poor linguistic theoretical basis (Biber et al., 2011). Based on corpus-based studies, researchers found out that clausal features (i.e., dependent clauses) were more frequent in conversations, whereas phrasal modifications in noun phrases tend to be the most important linguistic features in academic writing (Biber \& Conrad, 2002; Biber et al., 2011; Biber et al., 2013). The T-unit-based measure starts to lose its authenticity in measuring academic writing, because it can only capture simple subordination of clauses rather than complexity of phrasal modification.

Since 2010, linguists have carried out many corpus studies to discover historical change of noun phrase complexity in different registers, such as academic writing, newspapers, and magazines, to name a few (Biber \& Conrad, 2009). According to Biber and Gray (2010), academic writing is a very interesting register, because the historical change of noun phrases is much more pronounced in this register than other registers. The results of the studies demonstrate that nouns and nominalizations are much more frequent in academic research papers in various disciplines (e.g., science and humanities) in recent times than in the 19th century (Biber \& Conrad, 2009; Biber \& Gray, 2013). Biber and Gray (2011) pinpoints that some noun modifiers are used more frequently in academic writing, including noun as modifier, prepositional phrase, relative clause, and prepositional phrase followed by nonfinite clause. In 2011, a hypothesized developmental index of L2 writing was proposed. In the index, there are altogether five developmental stages of L2 writing and each stage incorporates several linguistic features frequently used by L2 writers at this particular proficiency stage (Biber et al., 2011). Among these linguistic features, 12 types of noun modifiers are identified in four developmental stages (except stage 1) in the index. The 12 types of noun modifiers in the index can be divided into two categories, namely pre-noun modifier and post-noun modifier (Biber \& Conrad, 2002). Generally, most pre-noun modifiers are found in lower stages, whereas post-noun modifiers are found in higher stages.

To the best of the author's knowledge, Parkinson and Musgrave (2014) carried out the first and the only research in the field of applied linguistics with a particular emphasis on discovering noun phrase complexity based on the developmental index of L2 writing. Their research involves 21 international students in a program of English for Academic Purposes (EAP) and 16 international students in the MA TESOL program at Victoria University of Wellington in New Zealand. They found out a difference in the use of noun modifiers between EAP students and MA TESOL students: EAP students rely heavily on some noun modifiers in the early stages of the index (e.g., attributive adjectives in stage 2), whereas MA TESOL students used more noun modifiers in advanced stages (e.g., prepositional phrases in stage 4) in their essays. Having said this, there are two limitations in this research coming from two intervening variables (i.e., topic and external help). First, Parkinson and Musgrave use academic writings in different topics in their study. The different topics are very likely to influence the use of noun modifiers in participants' essays (Parkinson \& Musgrave, 2014). Second, the final drafts of the essays are used as texts to be analyzed in this study. Since all the participants are nonnative speakers, they may ask for help from writing tutors or native speakers to improve their writings. Consequently, 
the use of noun modifiers may not accurately mirror the real L2 writing proficiencies of the participants in this research.

To deal with the limitations in Parkinson and Musgrave (2014), the author in this study investigated the relationship between L2 writing proficiency and noun modifications by using the essays in Fall 2014's Program of Intensive English (PIE) placement test at Northern Arizona University (NAU). By doing this, the author managed to control the two intervening variables (i.e., topics and external help) identified in the previous research, because all PIE students completed their test essays in the same time (i.e., 30 minutes) on the same topic without extra help from others.

\section{Research Question}

The research question is:

Do students with different L2 writing proficiencies use the noun modifiers in the developmental index of L2 writing with different frequencies in their test essays?

\section{Methods}

\section{Participants}

The participants in this research are 84 PIE students who took a placement level test at the beginning of Fall 2014 (see Table 1). They are from five different countries, including China, Saudi Arabia, Brazil, Korea, and Japan. The participants are from six different PIE levels, demonstrating the diversity of their comprehensive L2 proficiencies. Level 1 is the lowest level and level 6 is the highest level. Most participants are very young, from 18 to 24 years old, and only a few of them are older than 25 years old.

Table 1

Information of the Participants

\begin{tabular}{lllllr}
\hline Country & No. & PIE Level & No. & Age & No. \\
\hline China & 37 & Level 1 & 4 & $18-24$ & 79 \\
Saudi Arabia & 24 & Level 2 & 6 & $24-30$ & 5 \\
Brazil & 19 & Level 3 & 12 & & \\
Japan & 2 & Level 4 & 22 & & \\
Korea & 2 & Level 5 & 26 & & \\
& & Level 6 & 14 & & \\
\hline
\end{tabular}

Before the test, the participants got the same instruction from PIE instructors on the test, and during the test, all participants finished the essays on the same topic in the same time (i.e., 30 minutes) by hand writing.

\section{Texts}

The texts used in this research are the essays from the independent writing section of the NAU PIE placement level test in Fall 2014. The independent writing section is only to assess students' L2 writing proficiency instead of integrating other language skills. There are 84 essays selected from the total 140 essays based on students' consent of participating in PIE research. The lengths of the essays vary a great deal (see Table 2). 
Table 2

Basic Information of the Texts

\begin{tabular}{lll}
\hline Length & Mean length & 163 \\
\hline & Standard deviation & 19.42 \\
& Max length & 273 \\
Score & Min length & 67 \\
& Score range & $1-4$ \\
& Mean score & 2.2 \\
\hline
\end{tabular}

\section{Procedure}

Four main steps have been done to analyze the data in this research: (1) grouping participants, (2) selecting noun modifiers, (3) building and processing corpus, and (4) having a statistical analysis.

First, the essays used in the research were divided into two groups based on the mean of the 84 scores. To be more specific, the mean score (i.e., 2.2) was used as a cut point to split the participants in two groups. Group 1 has lower scores (i.e., 1, 1.5, and 2), whereas Group 2 has higher scores (i.e., 2.5, 3, 3.5, and 4). As the PIE placement level test is a proficiency test, the scores that participants got on the independent writing section should mirror their L2 writing proficiencies. Thus, it can be concluded that Group 1 has lower L2 writing proficiency, whereas Group 2 has higher L2 writing proficiency.

Second, 12 noun modifiers were selected from all the linguistic features in the hypothesized developmental index of L2 writing (Biber et al., 2011). Based on Parkinson and Musgrave (2014), participial pre-modifiers share some common features with attributive adjectives. As a result, participial pre-modifiers were added to the noun modifiers of the stage 2 . All of the 12 noun modifiers in this research were categorized into four groups based on the L2 writing developmental stages (see Table 3).

Table 3

Features and Positions of Noun Phrase Modifications

\begin{tabular}{llll}
\hline Stage & Noun modifiers & Position & Example \\
\hline 2 & Attributive adjectives & Pre & Big table \\
& Participial pre-modifiers & Pre & Exciting game \\
& Relative clauses & Post & The man who is driving \\
& Nouns & Pre & Rice cooker \\
& Possessive noun & Pre & Judy's book \\
& Prepositional phrases (concrete meaning) & Post & The capital of China \\
& Nonfinite clauses & Post & The questions confusing me \\
& Prepositional phrases (abstract meaning) & Post & The role of honesty \\
& Prepositional phrase + nonfinite clauses & Post & The policy of shutting it down \\
& Noun complement clauses & Post & The idea that we stay here \\
& Appositive noun phrases & Post & My best friend, Cody \\
& Infinitive clauses & Post & Two hours to go \\
\hline
\end{tabular}

Note. "Pre" means pre-modifiers and "post" means post-modifiers.

Third, the author built a corpus based on the 84 test essays, containing two sub-corpora for the lower-proficiency group and higher-proficiency group respectively. The two sub-corpora were tagged by the Biber Tagger (i.e., a corpus tagging program) and then two types of information were shown in the tagged 
corpus, namely original texts on one column and all tagging information related to the original texts on the other column (see Appendix A). Then, a computer program was written by Perl (i.e., a programming language) to automatically count the frequencies of the 12 noun modifiers by checking the tagging information in the tagged corpora. After that, the output of the counting program was manually checked to make sure the frequencies were accurate.

Fourth, all frequencies associated with the 12 noun modifiers were first normalized to 1,000 words and then put into the Statistical Package for the Social Science (SPSS). This is to figure out whether there are significant differences in the numbers of the 12 noun modifiers between the two groups. The author created 20 variables in SPSS (i.e., group ID, test scores, normalized frequencies for pre and post noun modifiers, normalized frequencies for four stages, and normalized frequencies for the 12 noun modifiers). Then, the normality of the variables was tested through Q-Q plot, aiming at selecting the parametric (i.e., t-test) or nonparametric (i.e., Mann Whitney $U$ test) statistical test. After that, the Mann Whitney $U$ test was used to explore whether there are significant differences, because the visual results of Q-Q plot show no normal distributions of the variables.

\section{Analysis}

In terms of research design, this research is based on a between-group design. It includes two groups, namely Group 1 and Group 2 (i.e., lower L2 writing proficiency group and higher L2 writing proficiency group). The independent variable is students' L2 writing proficiency, either at lower level or higher level. The dependent variable is the frequencies of the 12 noun modifiers. In order to answer the research question, the comparison was made on the frequencies of the 12 noun modifiers between the two corpora. The frequencies were from the outputs of the computer-counting program. With this comparison done, a relationship can be established between the use of noun modifiers and the participants' L2 writing proficiencies.

\section{Results}

This section provides detailed statistics to show the differences in the numbers of the noun modifiers between Group 1 (i.e., the lower L2 writing proficiency group) and Group 2 (i.e., the higher L2 writing proficiency group).

First of all, Table 4 shows some basic information of the essays written by the two groups, including the numbers of the essays, the mean lengths of the essays, and the numbers of the noun modifiers in the essays. $Z$ value from Mann Whitney $U$ test is also provided below to show a statistical difference of noun modifiers between the two groups.

Table 4

Basic Information of the Essays

\begin{tabular}{lllll}
\hline Group & Number of essays & Mean length & Number of noun modifiers & Observed $z$ value \\
\hline 1 & 42 & 145 & 81.07 & $z_{\text {obs }}=-2.33$ \\
2 & 42 & 181 & 91.12 & \\
\hline
\end{tabular}

Note. The statistics of noun modifiers is normalized to 1,000 words. In the tests, $p=0.05$, two-tailed distribution is used. The observed $z$ value is round up to two digits after the decimal and the critical $z$ value is \pm 1.96 ; "obs" stands for observed.

According to Table 4, Group 2 produced 181 words in their essays, whereas Group 1 only produced 145 words, 36 words less than Group 2 produced. For noun modifiers, Group 2 used around 10 more noun 
modifiers than Group 1 did per 1,000 words. The $z_{o b s}$ from Mann Whitney U test is -2.33 , which is greater than the critical $z$ value. Thus, Group 2 used noun modifiers statistically more than Group 1 did in 1,000 words.

In addition to the difference in the total numbers of noun modifiers, Table 5 shows the statistics related to two types of noun modifiers (i.e., pre-noun modifier and post-noun modifier). Basically, the two groups used pre-noun modifiers similarly but used post-noun modifiers very differently (see Table 5 ).

Table 5

Statistics of the Two Types of Noun Modifiers

\begin{tabular}{llll}
\hline Types of noun modifier & Group 1 & Group 2 & Observed $z$ value \\
\hline Pre-noun & 38.44 & 39.95 & $z_{\text {obs }}=-1.14$ \\
Post-noun & 42.63 & 51.17 & $z_{\text {obs }}=-2.37$ \\
\hline
\end{tabular}

Note. The statistics of noun modifiers is normalized to 1,000 words. In the tests, $p=0.05$, two-tailed distribution is used. The observed $z$ value is round up to two digits after the decimal and the critical $z$ value is \pm 1.96 .

For pre-noun modifiers, the frequencies of the two groups are very close to each other (i.e., 38.44 and 39.95). The $z_{o b s}$ is -1.14 , which is less than the critical $z$ value. Thus, there is no significant difference in the numbers of pre-noun modifiers produced by the two groups. In contrast, Group 2 used around 10 more post-noun modifiers than Group 1 did. The $z_{o b s}$ is -2.37 , greater than the critical $z$ value. Therefore, Group 2 used post-noun modifiers statistically more than Group 1 did in their essays.

Moreover, Table 6 offers the frequencies and $z$ values for the noun modifiers of four L2 developmental stages in the index, from stage 2 to stage 5 .

Table 6

Statistics of the Noun Modifiers at Each Stage

\begin{tabular}{llll}
\hline Stage & Group 1 & Group 2 & Observed $z$ value \\
\hline 2 & 36.45 & 37.73 & $z_{o b s}=-0.79$ \\
3 & 17.30 & 22.80 & $z_{o b s}=-1.92$ \\
4 & 17.88 & 22.25 & $z_{o b s}=-2.68^{*}$ \\
5 & 9.44 & 9.27 & $z_{o b s}=-3.70^{*}$ \\
\hline
\end{tabular}

Note. The statistics of noun modifiers is normalized to 1,000 words. In the tests, $p=0.05$, two-tailed distribution is used. The observed $z$ value is round up to two digits after the decimal and the critical $z$ value is \pm 1.96 . The $z$ values with an asterisk are greater than the critical $z$ value.

The frequencies of stage 2's noun modifiers are very similar between the two groups, 36.45 and 37.73 . In contrast, the raw frequencies of noun modifiers for the other three stages are different between the two groups: 17.30 and 22.80 (stage 3), 17.88 and 22.25 (stage 4), and 9.44 and 9.27 (stage 5). However, by checking the $z_{o b s}$ values, only two of them are greater than the critical $z$ value, which are -2.68 (stage 4) and -3.70 (stage 5). Consequently, it can be concluded that there are no significant differences in the frequencies of noun modifiers at stage 2 and stage 3 between Group 1 and Group 2. However, for stage 4, Group 2 used the noun modifiers statistically more than Group 1 did. For stage 5, Group 2 produced the noun modifiers statistically less than Group 1 did.

Last, to be more specific, Table 7 demonstrates the statistics of all the 12 noun modifiers in the developmental index of L2 writing. The raw frequencies and observed $z$ values are all provided in the table. 
Table 7

Statistics of the 12 Noun Modifiers

\begin{tabular}{llccl}
\hline Stage & Noun modifier & Group 1 & Group 2 & Observed $z$ value \\
\hline 2 & Attributive adjectives & 36.45 & 36.52 & $z_{o b s}=-0.76$ \\
& Participial pre-modifiers & 0.00 & 0.28 & $z_{\text {obs }}=-1.42$ \\
3 & Relative clauses & 5.52 & 9.02 & $z_{o b s}=-2.07^{*}$ \\
& Nouns & 1.02 & 1.79 & $z_{o b s}=-0.30$ \\
& Possessive noun & 1.07 & 2.46 & $z_{o b s}=-1.45$ \\
& Prepositional phrases (concrete meaning) & 9.79 & 10.63 & $z_{o b s}=-2.04^{*}$ \\
4 & Nonfinite clauses & 0.00 & 0.14 & $z_{o b s}=-1.00$ \\
& Prepositional phrases (abstract meaning) & 17.88 & 22.11 & $z_{o b s}=-2.61^{*}$ \\
5 & Prepositional phrase + nonfinite clause & 0.15 & 0.70 & $z_{o b s}=-1.63$ \\
& Noun complement clauses & 0.30 & 0.96 & $z_{o b s}=-1.16$ \\
& Appositive noun phrases & 0.15 & 0.14 & $z_{o b s}=-0.02$ \\
& Infinitive clauses & 8.84 & 7.47 & $z_{o b s}=-5.60^{*}$ \\
\hline
\end{tabular}

Note. The statistics of noun modifiers is normalized to 1,000 words. In the tests, $p=0.05$, two-tailed distribution is used. The observed $z$ value is round up to two digits after the decimal and the critical $z$ value is \pm 1.96 . The $z$ values with an asterisk are greater than the critical $z$ value.

In the table, the frequencies of the 12 noun modifiers present a very complicated situation. However, some noun modifiers share common features, which can be summarized into three types: noun modifiers with low frequencies (i.e., normalized frequency is less than 1), noun modifiers with similar frequencies, and noun modifiers with significant differences in their frequencies. There are five noun modifiers rarely used by both groups (see Figure 1).

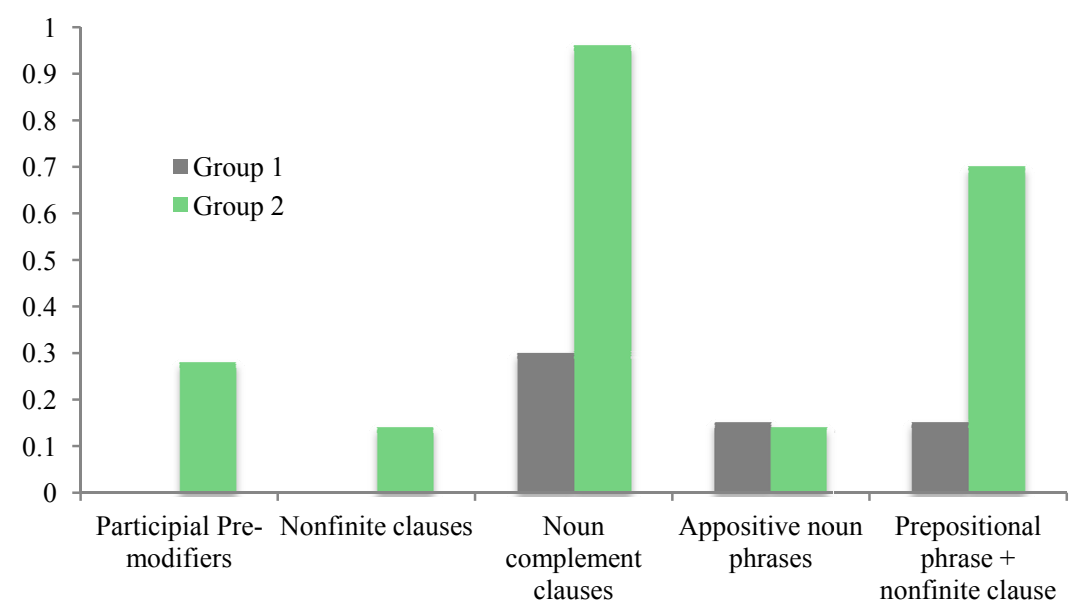

Figure 1. Low-frequency noun modifiers. The frequencies are normalized to 1,000 words.

All the normalized frequencies here are lower than 1.

Based on Figure 1, these noun modifiers are participial pre-modifiers, nonfinite clauses, prepositional phrases followed by nonfinite clauses, noun complement clauses, and appositive noun phrases. Their normalized frequencies are all less than 1 in both groups' essays, with the greatest frequency of 0.96 and the least frequency of 0 . As a result, all the participants do not effectively use these five noun modifiers.

Apart from the low-frequency noun modifiers, attributive adjectives are a type of noun modifier used by the two groups in similar frequencies, namely 36.45 and 36.52. The observed $z$ value of attributive adjectives 
(i.e., -0.76) is much less than the critical $z$ value. Noun as modifiers and possessive noun as modifiers also have similar but low frequencies (between 1 and 3). They observed $z$ values (i.e., -0.30 and -1.45 ) also indicate that there are no significant differences in their frequencies between the two groups.

However, the two groups used some noun modifiers very differently. There are significant differences in four noun modifiers between the two groups based on their observed $z$ values. The noun modifiers include relative clauses $\left(z_{o b s}=-2.07\right)$, prepositional phrases expressing concrete meaning $\left(z_{o b s}=-2.04\right)$, prepositional phrases expressing abstract meaning $\left(z_{o b}=-2.61\right)$, and infinitive clauses $\left(z_{o b s}=-5.60\right)$. In light of relative clauses and prepositional phrases, Group 2 used them statistically more than Group 1. Infinitive clauses have an opposite situation in that Group 1 used it statistically more than Group 2 did in their essays.

In light of infinitive clauses in stage 5, it is surprising that Group 1 (i.e., the lower L2 writing proficiency group) produced this type of noun modifiers statistically more than Group 2 (i.e., higher L2 writing proficiency group). The observed $z$ value (i.e., -5.60) is much greater than the critical $z$ value. By checking the prompt of the independent writing section of Fall 2014 PIE placement level test, the author noticed that the writing prompt contains an example of infinitive clauses as noun modifier. In fact, students in both groups just paraphrased the sentence that has infinitive clause as noun modifier to use it at the beginning of their essays (see Appendix B). Figure 2 compares the frequencies of original infinitive clause and the frequencies of infinitive clause not from paraphrasing the writing prompt.

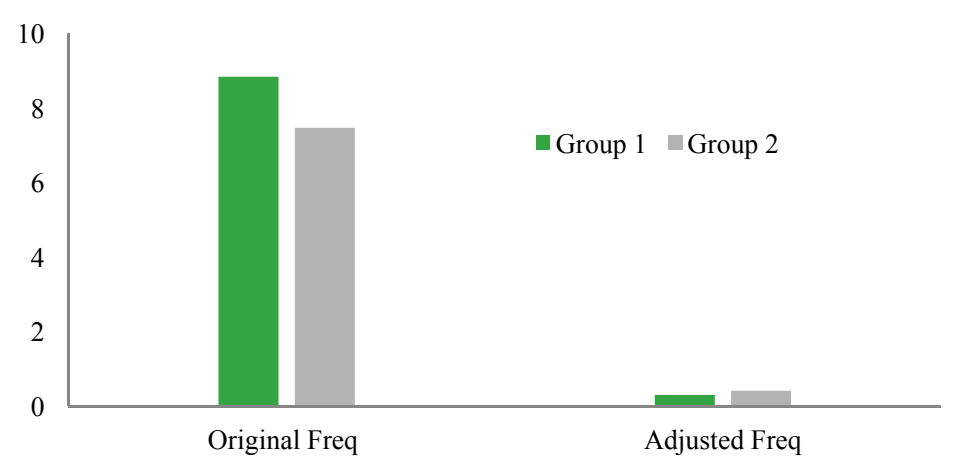

Figure 2. Original and adjusted frequencies of infinitive clauses. The adjusted frequency means the frequency of infinitive clauses not from paraphrasing the writing prompt. The frequencies are normalized to 1,000 words.

The original frequencies are the same as the frequencies shown in Table 7 and they are around 8 . However, the adjusted frequencies are 0.31 and 0.42 for Group 1 and Group 2, respectively. Thus, infinitive clauses are also a noun modifier rarely produced by the two groups. Consequently, there is also no difference in these adjusted frequencies of infinitive clauses between Group 1 and Group 2.

\section{Discussion}

Based on the results, three general points can be reasonably summarized. First, students with higher L2 writing proficiency are able to produce longer essay and they can use much more noun modifiers in their essays. A reasonable explanation to this point is that higher-proficiency students are more capable of elaborating their sentences they want to express by using appropriate noun modifiers. Sometimes, students with higher L2 writing proficiency can even use fairly complex noun phrases by combining different types of noun modifiers. In contrast, this combination can rarely be found in the essays written by students with lower L2 writing 
proficiency. A quick example to illustrate this difference is "an important issue that influences life styles of different people" (Group 2) versus "an issue" (Group 1).

Second, students with higher L2 writing proficiency particularly tend to use much more post-noun modifiers. It is easy to notice that most post-noun modifiers are at upper-intermediate or advanced stages (i.e., stage 4 and stage 5). Students with higher L2 writing proficiency not only use post-noun modifiers for expressing more accurate meaning, but also use it for a purpose of balancing grammatical structure. They tend to use post-noun modifiers to make heavy ends for their sentences (e.g., it is the best way of considering what the difference between people is). To be more specific, the two types of post-noun modifiers (i.e., relative clauses and prepositional phrases expressing both concrete and abstract meaning) seems to have the potential to be an indicator for students' L2 writing proficiencies, because the results shows that students with higher L2 writing proficiency are able to use them more in their essays for both purposes of modifying meanings and balancing sentence structure.

Third, students with both higher and lower L2 writing proficiencies in this research barely have ability of using six noun modifiers, namely participial pre-modifiers, nonfinite clauses, prepositional phrases followed by nonfinite clauses, infinitive clauses, noun complement clauses, and appositive noun phrases. This can be ascribed to the lack of explicit instructions on these linguistic features at PIE. Most PIE's writing classes focuses on writing organization, writing coherence, and writing content, rather than paying so much attention to a specific series of grammatical point. In this case, students' awareness of using noun modifiers is not effectively aroused by taking PIE classes. Therefore, these six noun modifiers are hard grammatical points for all PIE students.

\section{Pedagogical Implications}

Three pedagogical implications can be made from the results of the research. First, PIE teachers should generally give more explicit instructions on post-noun modifiers. It is necessary for students with lower L2 writing proficiency to get instructed on the post-noun modifiers to enhance their L2 writing proficiency. It is also strongly recommended that PIE teachers keep track of how students use the two types of linguistic features, namely clauses with non-predictive verbs (i.e., ing/ed clauses and to-do clauses) and linguistic devices supplementing meanings of head nouns (i.e., noun complement clauses and appositive noun phrases). This is mainly due to the fact that these are the noun modifiers having extremely low normalized frequencies in all the participants' essays. Such instructions will be helpful for PIE students to improve their sensitivity of using advanced noun modifiers in the future. Therefore, the more instructions on noun modifiers, the more progress students may make on their L2 writing.

Second, teachers should think about arranging English writing workshops to PIE students. Since the PIE students are placed into different levels based on their comprehensive L2 proficiencies instead of their L2 writing proficiencies, it is justifiable to assume that a PIE student probably cannot get writing instruction catering to his particular writing proficiency level. Students may not improve their English writing effectively with only instruction in their regular writing class. A potential problem is that students who are at stage 2 may be taught with noun modifiers from stage 4 or 5 . With no scaffolding instruction on these advanced noun modifiers, students could not effectively enhance their writing and are even demotivated by the class instruction. To solve this problem, PIE faculty members should organize different English writing workshops for students 
with different L2 writing proficiencies, to teach the specific noun modifiers they need. For example, in terms of the lower proficient students in this research, a scaffolding writing workshop with emphasis on relative clauses and prepositional phrases would be effective for their improvement of English writing ability.

Third, PIE teachers should pay attention to design appropriate test prompts for writing sections of tests. Many students, especially students with lower L2 writing proficiency, frequently copied and used the words, expressions, and sentences in a test prompt. In this research, the author also realized that many students repeatedly used the noun modifiers in the test prompt, for example, "the way to learn about life". Even though this is a modifier in advanced stage (i.e., Stage 5), it is not reasonable to conclude that students all develop their L2 writing proficiencies very well. Such a situation probably has a negative influence on grading of test essays, especially on grading grammar. Consequently, particular attention should be paid to prompt design for a writing section in a language proficiency test.

\section{Conclusion and Limitations}

Overall, students with different L2 writing proficiencies use noun modifiers differently. Proficient students tend to use more post-noun modifiers and noun modifiers at higher stages in the L2 writing index, including relative clauses and prepositional phrases. For the noun modifiers in lower stages, students with different L2 writing proficiencies produced them in a similar amount in their essays (e.g., attributive adjectives). However, some noun modifiers are very hard for all students, namely nonfinite clauses, infinitive clauses, appositive noun phrases, noun complement clauses, and prepositional phrases followed by nonfinite clauses. All students rarely used any of these noun modifiers in their essays. It is suggested that English as a second language (ESL) teachers may pay close attention to provide explicit instructions on the use of noun modifiers in their classes. By doing this, students could improve their L2 writing proficiency effectively.

In terms of limitations, the research question in this study is a yes-no question. The author was only to investigate whether or not there is a significant difference in using the noun modifiers between students with different L2 writing proficiencies. Research on the topic should be carried out from a different research perspective. The research question could be, "To what extent, do students having different L2 writing proficiencies differently use the 12 noun modifiers in the developmental index of L2 writing in their essays?" The idea of effective size will be helpful for the author to do future research. Also, instead of running a Mann Whiney U test, a correlation test (i.e., bivariate test) could be used to find out, to what extent, there is a correlation between L2 writing proficiency and noun modifications.

\section{References}

Biber, D., \& Conrad, S. (2002). Longman student grammar of spoken and written English (p. 264). Harlow, Essex: Longman.

Biber, D., \& Conrad, S. (2009). Written registers, genres, and styles. In Register, genre, and style (p. 116). Cambridge: Cambridge University Press.

Biber, D., \& Gray, B. (2010). Challenging stereotypes about academic writing: Complexity, elaboration, explicitness. Journal of English for Academic Purposes, 9, 2-20.

Biber, D., \& Gray, B. (2011). Grammatical change in the noun phrase: The influence of written language use. English Language and Linguistics, 15(2), 223-250.

Biber, D., \& Gray, B. (2013). Being specific about historical change: The influence of sub-register. Journals of English Linguistics, 41, 1-31.

Biber, D., Gray, B., \& Poonpon, K. (2011). Should we use characteristics of conversation to measure grammatical complexity in L2 writing development. TESOL Quarterly, 45(1), 5-35. 
Biber, D., Gray, B., \& Poonpon, K. (2013). Pay attention to the phrasal structures: Going beyond t-units-A response to WeiWei Yang. TESOL Quarterly, 47(1), 192-201.

Huddleston, R. (1984). Introduction to the grammar of English. Cambridge, England: Cambridge University Press.

Hunt, K. W. (1965). Grammatical structures written at three grade levels. Champaign, IL: National Council of Teachers of English.

Parkinson, J., \& Musgrave, J. (2014). Development of noun phrase complexity in the writing of English for academic purposes students. English for Academic Purpose, 14, 48-59.

\section{Appendix A: An Excerpt of the Tagged Corpus}

\begin{tabular}{|c|c|}
\hline I & ${ }^{\wedge} \mathrm{pp} 1 \mathrm{a}+\mathrm{pp} 1+++=\mathrm{I}$ \\
\hline think & $\wedge_{\mathrm{vb}}+\mathrm{vprv}+++=$ think \\
\hline the & $\wedge$ ati $++++=$ the \\
\hline pest & $\wedge_{\mathrm{jjt}}+\mathrm{atrb}+++=$ best \\
\hline way & ${ }^{\wedge} \mathrm{nn}++++=$ way \\
\hline $\mathrm{o}$ & $\wedge_{\text {to }}++++=$ to \\
\hline earn & ${ }^{\wedge}$ vbi + vprv $+++=$ learn \\
\hline about & $\wedge_{\mathrm{rb}++++=\text { about }}$ \\
\hline life & ${ }^{\wedge} \mathrm{nn}++++=$ life \\
\hline is & ${ }^{\wedge} \mathrm{vbz}+\mathrm{bez}+\mathrm{vrb}++=\mathrm{is}$ \\
\hline by & $\wedge$ in $++++=$ by \\
\hline listening & ${ }^{\wedge} \mathrm{nn}++++=$ listening \\
\hline 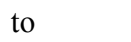 & $\wedge$ in $++++=$ to \\
\hline the & $\wedge$ ati $++++=$ the \\
\hline advice & ${ }^{\wedge} \mathrm{nn}++++=$ advice \\
\hline c & $\wedge$ in $++++=$ of \\
\hline family & 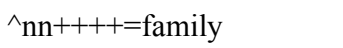 \\
\hline and & $\wedge \mathrm{cc}++++=$ and \\
\hline friends & ${ }^{\wedge}$ nns $++++=$ friends. \\
\hline
\end{tabular}

Appendix B: The Concordances From AntConc

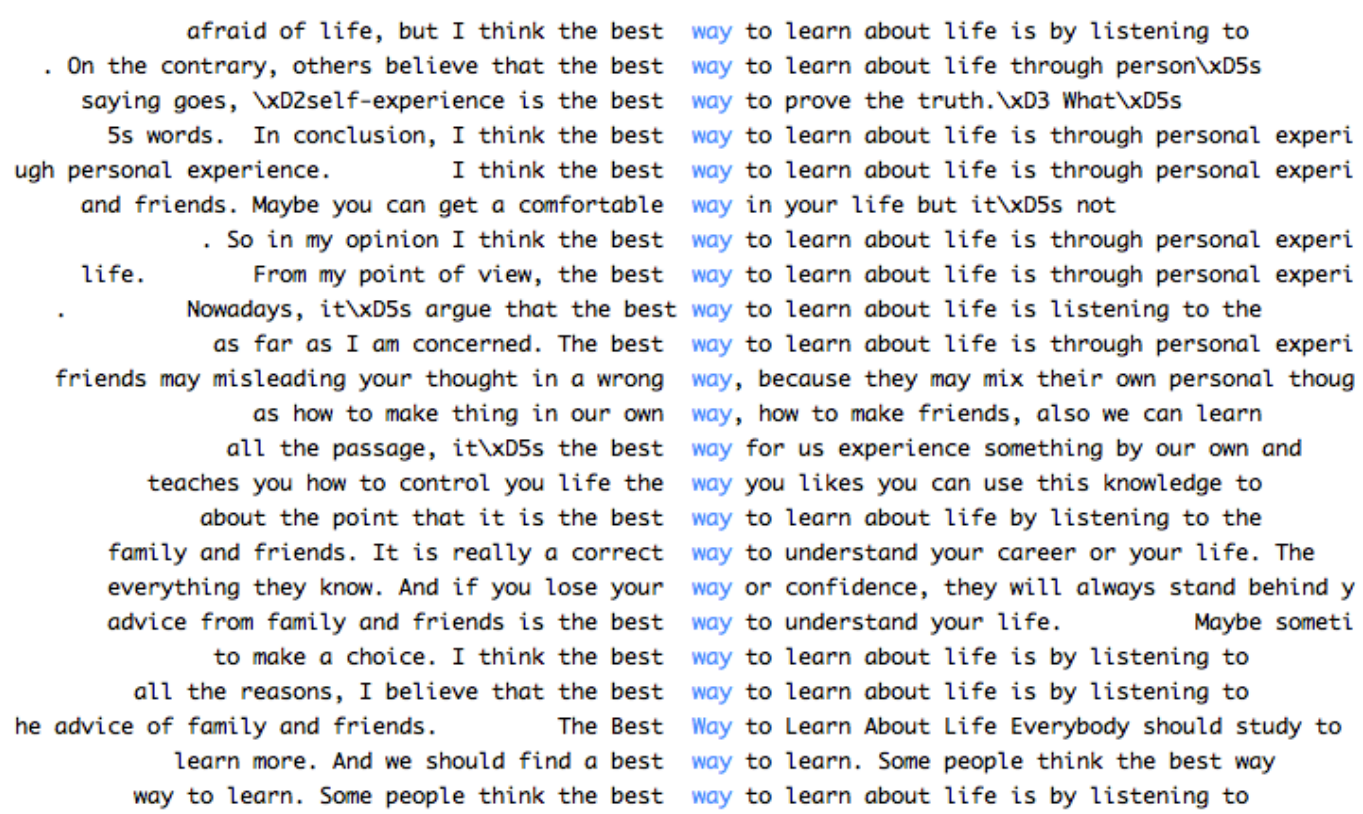

